\title{
Role of local government in the power facilities management
}

\author{
Elena Ushakova ${ }^{1}$, Elena Fugalevich $^{1}$, Elena Voronina $^{1}$, Marina Mihailova ${ }^{1}$, Olga Kim $^{1, *}$ \\ ${ }^{1}$ Saint Petersburg University of Management Technologies and Economics, Institute of Management \\ Economics and Information Technology, 190103, Russia \\ ${ }^{1}$ Saint-Petersburg State University of Economics, Institute of Management, Russia
}

\begin{abstract}
On the basis of the conducted research, the authors proposed some approaches of interaction between local governments, population and economic entities in the field of environmental protection as a necessary element of development of the energy sector. A special place in this article is given to such form of interaction as public hearing. Also, the article presents proposals to improve public hearings.
\end{abstract}

\section{Introduction}

This article is devoted to the interaction of local governments, the population and economic entities in the energy sector. Human nature-related needs are growing, and the resources needed are being depleted many times faster than replenished. Therefore, it is necessary to regulate human intervention in nature, to provide citizens with more information about the ways of preserving the environment, to encourage people to protect and preserve nature.

Constant pollution of atmospheric air, surface water and groundwater, soil and vegetation leads to the degradation of ecosystems and the reduction of the biosphere productive capacity.

Usually, constitutions (charters) and laws on the organization of local government on the territory of a federal subject of the Russian Federation establish basic provisions that designate in the most general form the subjects of jurisdiction of municipal authorities in the energy field. Special laws on the protection of the environment of the federal subject of the Russian Federation, as well as on certain types of ecologically significant activities, specify the above-mentioned basic authority.

Purpose of the research: to analyze the form of interaction between local governments, population and economic entities in the field of environmental protection and to develop a practical proposal for their improvement aimed at the development of the energy sector.

Strategic facilities in the territory of this municipal formation include the Leningrad Nuclear Power Plant (LNPP) and the Leningrad Branch of the branch North-West Territorial Okrug of FSUE RosRAO (which operates storages for radioactive waste, spent sources of ionizing radiation and spent nuclear fuel) that directly impact the environment of the north-western region and, in particular, of the municipal formation under consideration.

\footnotetext{
*Corresponding author: ol_kim@hotmail.com
} 


\section{Research methods}

In the course of the study, the authors used the method of analysis, survey methods (expert assessment method and questionnaire methods), as well as the method of ranking.

The management of the Leningrad Nuclear Power Plant engages actively with authorities of different levels. As part of this work, LNPP holds monthly meetings with the heads of the municipal formation and administration of Sosnovoborsky urban okrug and their deputies. The Information and Public Relations Department of the plant makes comprehensive efforts to maintain constructive relationships with the authorities in various areas:

- 6 employees of the Leningrad NPP are deputies and assistants to deputies of the local council of Sosnovy Bor town;

- representatives of the Youth Organization of the plant represent the Leningrad Nuclear Power Plant in the Council of Youth Organizations of Sosnovy Bor town and serve as assistants to deputies of the Sosnovy Bor Council of Deputies.

The Leningrad NPP and the administration of Sosnovoborsky urban okrug jointly host delegations from different regions of Russia and foreign countries visiting through State Atomic Energy Corporation ROSATOM and Rosenergoatom Concern JSC within the framework of the Russian Nuclear Energy Development Program.

The Department of Information and Public Relations of LNPP actively cooperates with:

- the Government of the Leningrad Oblast within the framework of organizing and conducting various projects and activities, including environmental ones;

- the Department of Rosprirodnadzor for the North-West Federal District, the North-West Center for Support of Environmental Education, the Public Council under the Governor of the Leningrad Region, the Public Reception of State Atomic Energy Corporation ROSATOM and the administration of Sosnovy Bor;

- the Education Committee of Sosnovy Bor to implement educational and vocational guidance programs for schoolchildren and students;

- the department of culture of Sosnovy Bor to carry out creative and cultural events; the Department for Youth, Sports and Tourism to implement the youth policy of the Leningrad NPP, as well as tourism and sports events;

- the Department of Environmental Management and Protection to hold public participations, round tables and thematic seminars for specialists and representatives of public environmental organizations, to run environmental campaigns and events.

In addition, plant's employees actively participate in mass town events, including environmental ones.

LNPP strives to ensure a high level of openness and transparency of its activities, implementing for this purpose the principle of active dialogue with interested parties. LNPP also strives to maintain active communication with all interested parties, provide timely information on all aspects of activities and respond to requests and wishes of interested parties.

Interaction with the interested parties is based on the principle of regular and constructive dialogue, partnership, mutually beneficial cooperation, trustworthiness and sincerity, publicity and transparency, fulfillment of the obligations undertaken.

LNPP actively cooperates with public environmental organizations that have a real opportunity to obtain objective information about the ecological, radiation and energy safety of LNPP.

Since 2013, Stakeholder Commission established at the initiative of the Concern has been working to improve the public reporting system and the public acceptability of the Concern's activities by engaging interested parties (stakeholders) in a dialogue. 
The Information and Public Relations Department of the Leningrad NPP regularly invites representatives of public and environmental organizations to participate in environmental forums and conferences, meetings, public participations, etc. [13] [10].

The key objectives for working with the public and target audiences are:

- development and strengthening of stable partnership relations between LNPP and local authorities, public organizations, mass media and the public in the region where Leningrad NPP is located;

- demonstrating safety and environmental acceptability of the Leningrad NPP and nuclear power in general, creation and maintenance of a positive image of the enterprise and increasing the attractiveness of working in the field of nuclear power;

- formation and maintenance of a favorable informational background for covering the activities of the Leningrad Nuclear Power Plant and nuclear power so that people can make conscious decisions on the protection of their interests, on environmental safety and health protection issues and on countering information terrorism against nuclear power facilities;

- improvement of the ecological state of the water area of the Gulf of Finland, rivers, lakes and their coastal territory in order to make them attractive for the rest of the townspeople.

Last year, the Information and Public Relations Department of the Leningrad NPP, in conjunction with the human resources of the plant, continued to work systematically to attract graduates from schools, universities and vocational schools to the enterprise and to ensure that young specialists continue to work at the production. In 2016, 13 vocational guidance visits to the plant were held for 135 senior pupils of town's schools. Informational and educational seminars, practical training, information visits, etc. are organized in the departments of the Leningrad Nuclear Power Plant for the students of the field-specific universities. The quality of education, guaranteed employment, interesting work with an opportunity to advance, occupational mobility, concern for safety and health, a combination of traditions and innovations offered by LNPP should inevitably catch the interest of young people with an inclination for technical disciplines.

In 2016 specialists of the Information and Public Relations Department of the Leningrad Nuclear Power Plant organized and conducted about 250 information, educational, vocational guidance visits, technical and targeted tours to operating and workin-progress construction facilities of the Leningrad NPP for 2,700 guests.

LNPP interaction with the media is based on the policy of maximum transparency and openness.

Information on the work of NPP and the radiation situation in the near-plant cities is available on the official website of the Concern (www.rosenergoatom.ru), where press releases and information messages are posted promptly.

LNPP also addresses the children's audience, which includes the following [13]:

1. All-Russian debate championship among schoolchildren "In the Zone of Special Attention." The debate is recognized by the teachers and specialists of LNPP as the most effective form of work with schoolchildren, which allows identifying gifted youth, providing it with methodological assistance in profession selection, promoting the personal development of adolescents by participation in discussions and public speeches.

2. Regional round of the International contest of scientific and educational projects "Power of the Future". Information and Public Relations Department of the Leningrad NPP traditionally promotes the organization and holding of the regional round of the contest "Power of the Future".

Senior pupils from Sosnovy Bor, St. Petersburg and Gatchina take part in the contest with both theoretical and practical research conducted by themselves. Mainly, the children's works are devoted to ecology and nuclear energy. 
3. "ROSATOM School". "ROSATOM School" project of State Atomic Energy Corporation ROSATOM started on the territory of Sosnovy Bor in 2011 is aimed at supporting the best and talented schoolchildren and teachers and at raising the educational level of all pupils and teachers of schools located in the territory of ROSATOM.

4. "Atom-Class" Project. The creation of "atom-classes" in schools in the areas of the location of nuclear power plants and closed administrative-territorial formations is part of the strategic program of vocational guidance and training of qualified personnel for the nuclear industry.

In 2016, the Information and Public Relations Department specialists continued to use the classical methods and applied new ones to inform the public [13][10]:

- with students: practical excursion classes on certain topics offered by universities with the involvement of specialists of the plant; on-site seminars on certain topics of the education program;

- with schoolchildren: educational thematic seminars; vocational guidance and educational projects;

- with teachers, doctors, municipal employees, environmentalists: information seminars on sectoral subjects, accompanied by discussion of thematic issues, delivery of information materials, leaflets and brochures and by excursions to the enterprise;

- with public and environmental organizations: on-site meetings where the exchange of views is accompanied by a visit to the sites under discussion; engagement of public environmental organizations in participation in thematic projects and events of ROSATOM State Corporation, Rosenergoatom Concern and Leningrad NPP;

- with young specialists of the region's enterprises: technical tours to Leningrad NPP for young specialists from St. Petersburg and Sosnovy Bor, organized and conducted by Information and Public Relations Department, as well as at the initiative of the youth organization of the plant, and exchange tours for young specialists of Leningrad NPP to the enterprises of the region;

- with the internal public, i.e. specialists of Leningrad NPP units: technical excursions for employees of the plant's units not directly related to the nuclear power plant's production process.

During 2016, 7 targeted press tours were organized with a total of 140 participants, more than 150 meetings with management and specialists of the Leningrad Nuclear Power Plant and the blocks under construction, Rosenergoatom Concern, ROSATOM State Corporation and Rostekhnadzor were held for representatives of local, regional and federal media (in the format of press conferences, press tours, briefings, comments for the media).

The Communications Department of the Leningrad Branch of the branch North-West Territorial Okrug of FSUE RosRAO delivers events to inform the general public and specialized professionals in Russia and abroad about the activities of the enterprise.

The main tasks are the coverage of the activities of the enterprise carried out in strict accordance with the norms of the federal legislation, raising the level of awareness of the population about the work performed and increasing the loyalty of the public groups towards the enterprise.

In the process of licensing the activities of the Leningrad Branch, obtaining permissive environmental documentation and conducting inspections, the branch actively cooperates with the local bodies of the Federal Service for the Supervision of Environment, Technology and Nuclear Management (Rostekhnadzor), the Federal Service for Surveillance on Consumer Rights Protection and Human Wellbeing (Rospotrebnadzor), the Federal Medical-Biological Agency, as well as with local governments.

\section{Results}


In the framework of this statistic the results of the research are that the authors have updated the ranking map of stakeholders in the field of environmental protection as a necessary element of the development of the energy sector and developed practical proposals to improve public and public hearings as forms of interaction between local governments, the population and economic entities in the energy sector. These scientific results will be discussed in more detail below.

According to the results of sociological surveys conducted by the Levada Center, the balance of positive and negative assessments of nuclear power development programs among the population of Russia in 2016 was 55.3\% (over the past five years, this indicator ranged from 49.2 to $62.1 \%$ ). The percentage of supporters of the use of nuclear power in Russia amounted to $71 \%$ (over the past five years, this indicator ranged from 66.5 to $75.5 \%$ ). Thus, the result of 2016 fits the general trend of recent years and confirms the population of Russia showing a consistently high level of support for nuclear power development programs [13] [10].

In 2017, the balance of positive and negative assessments remained unchanged.

In 2018, the balance of positive and negative assessments is expected to remain at 55$59 \%$.

While writing the article, the authors updated the ranking map of stakeholders (interested parties).

The interest is related to the expectations and needs of stakeholders.

Interaction with interested parties is based on the following principles:

- respect for the views of the interested party;

- provision of timely information to the interested parties;

- collaboration on the regular basis;

- compliance with commitments undertaken and demanding that the interested parties comply with them.

The objectives of the formation and analysis of the Stakeholder Map are the following:

- defining the contents of the report based not only on the activity purpose and experience of the enterprise, but also on the results of its activities, taking into account the reasonable expectations and interests of the main stakeholders;

- forming an audience of interested parties for conducting dialogues and public consultations;

- identifying the areas and forms of interaction with stakeholders that need additional measures to increase efficiency of interaction and mutual satisfaction;

- creating a base for monitoring and identifying trends in the stakeholders' rank changes.

The methodology for forming a Stakeholder Map comprises the following stages:

Stage 1 - defining the list of stakeholders with whom the local community interacts in the course of its activities;

Stage 2 - the initial ranking of this list of stakeholders based on the results of a "snapshot" poll of the enterprise's top management;

Stage 3 - refining the results of the "snapshot" poll based on the annual report on "The Strategy of Development..." implementation results.

The study should focus on the surroundings and the importance of stakeholders in achieving the results of interaction. Classification of stakeholders will allow us to outline the areas of their presence and their main interests.

Interested parties are shown in Figure 1.

The ranking map of the stakeholders of Leningrad NPP is shown in Figure 2.

The ranking map was compiled based on the results of the analysis performed. The values of the indices were in the range from 0 to 2 (significant indices are those that exceed 1). 


\begin{tabular}{|ll|}
\hline \multicolumn{1}{|c|}{ Interested parties } \\
\hline$\bullet$ & Federal authorities and authorities of the subjects of the Russian Federation, municipalities \\
\hline$\bullet$ & Supervisory authorities \\
\hline$\bullet$ & Shareholders (JSC Atomenergoprom, ROSATOM State Corporation) \\
\hline$\bullet$ & Employees, trade unions \\
\hline$\bullet$ & The population and local communities \\
\hline$\bullet$ & Environmental and public organizations \\
\hline$\bullet$ & Business partners and potential investors \\
\hline$\bullet$ & Media \\
\hline & Analysts, expert community \\
\hline
\end{tabular}

Fig. 1. Interested parties.

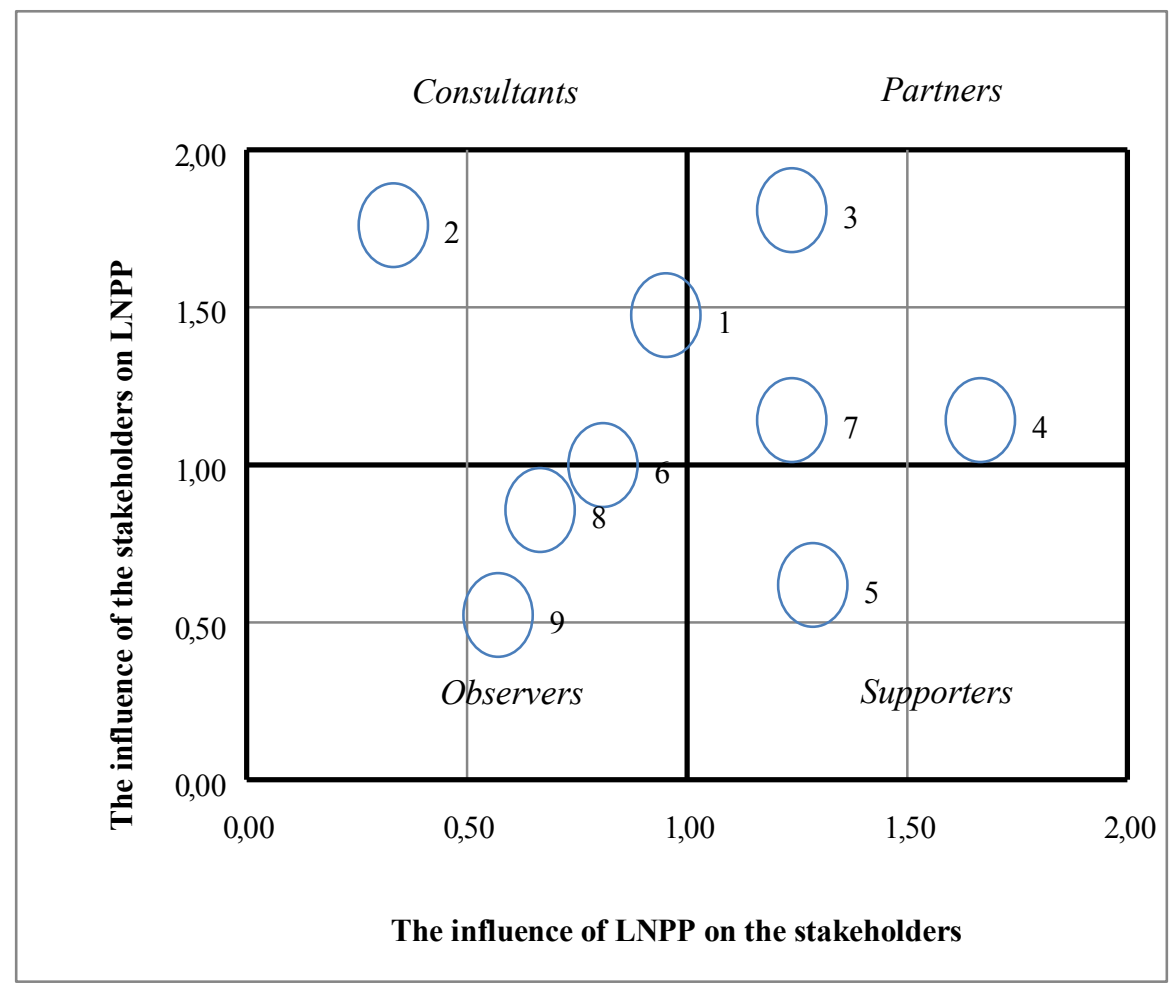

Fig. 2. Stakeholder Map (Ranking map of the stakeholders). 
The analysis-based map (Fig. 2) reflects the degree of influence of the stakeholders on LNPP and the degree of dependence of the stakeholders on LNPP.

The following stakeholders have the greatest influence on LNPP:

- federal authorities and authorities of the subjects of the Federation, municipalities;

- supervisory authorities;

- environmental and public organizations.

LNPP has the greatest influence on such interested parties as the population and local communities.

The Stakeholder Map presented supports efforts to plan and develop interaction and build relationships. The map helps to identify the interested parties of interaction and their impact on each other's functioning, and in fact it becomes a catalyst for the development of various ways of interaction.

Proceeding from the above, we propose to define the generalized ways of interaction between LNPP and the interested parties.

The following stakeholders placed into the "Consultants" group are supposed to interact with LNPP in the form of providing consultations to LNPP:

- federal authorities and authorities of the subjects of the Federation, municipalities;

- supervisory authorities;

- environmental and public organizations.

The following stakeholders placed into the "Partners" group are supposed to interact with LNPP in the form of partnership:

- federal authorities and authorities of the subjects of the Federation, municipalities;

- shareholders (JSC Atomenergoprom, ROSATOM State Corporation);

- employees, trade unions;

- business partners and potential investors.

The stakeholders placed into the "Supporters" group are supposed to interact with LNPP in the form of full awareness of their activities and engagement of the population and local communities in this activity, significant attention being paid to public discussions / public participations.

The following stakeholders placed into the "Observers" group are supposed to interact with LNPP in the form of mutual monitoring of the activities of the interested parties, as well as monitoring of their own activities:

- environmental and public organizations;

- media;

- analysts, expert community.

The research conducted and information obtained from the Ranking map of the stakeholders allow determining the ways of interaction and the needs of the interested parties. Understanding the interests of the stakeholders and describing the ways of interaction will help to develop an optimal strategy for interaction between the stakeholders and LNPP.

In the process of planning and carrying out its activities that have / can have rather strong impact on the environment and the local population, while always adhering strictly to the laws of the Russian Federation, LNPP periodically initiates public discussions (participations) [13] [10]. Their participants include experts from scientific and design organizations, representatives of supervisory authorities, federal, regional and local authorities and public organizations, environmental communities, journalists, as well as the public.

In 2016, a total of 15 public discussions with more than 6,700 participants took place in the regions where the Concern is present. Within each public discussion, more than 100 
events with the public, authorities and the media were held to explain the planned activities and the principles of their safety for human and the environment.

Educational seminars were held, including a seminar on preparation and holding of public participations for the nuclear industry leaders in Jordan and a seminar "Preparation and holding of public participations" for representatives of all NPPs and the Branch for the implementation of capital projects of the Concern with the participation of the informationanalytical agency BONAMENS.

Next, we will focus on the interaction of the branch North-West Territorial Okrug of FSUE RosRAO with public environmental organizations, scientific and social institutions, the population and authorities.

Within the framework of scientific and technical cooperation, including the work on the analysis of existing schemes for handling radioactive waste, developing proposals for its optimization and bringing it into compliance with the principles of a unified state system for radioactive waste management, the company cooperates with such leading institutions as FSUE NPO V.G. Khlopin Radium Institute, Open JSC All-Russian Scientific Research And Design Institute Of Energy Technology (VNIPIET), FSUE A.P. Aleksandrov Scientific Research Technological Institute's (NITI).

As part of the activities to inform the public, administration of Sosnovoborsky urban okrug holds public participations on such topics as:

- preliminary materials of the environmental impact assessment of the construction of a radiation source in the North-West Territorial Okrug FSUE RosRAO;

- materials of justification for the license (including materials of the environmental impact assessment) for the construction of a radiation source in the branch North-West Territorial Okrug of FSUE RosRAO.

As a result of public discussions (in the form of public participations), the working group headed by the chairman of the permanent deputy commission for ecology, architecture and town planning of the council of deputies of Sosnovoborsky urban okrug came to the conclusion that the public discussions (in the form of public participations) should be considered accomplished.

Presently, it is possible to identify such forms of interaction between local governments, the population and economic entities as "public discussions", "public participations" and "public hearings".

Proceeding from the foregoing, it is necessary to clarify the definitions of the terms "public discussions", "public participations" and "public hearings," each of them having its own characteristics.

Public discussions are conducted by the customer as part of the process of environmental impact assessment and are regulated by the Environmental Impact Assessment Regulation, and the procedure for their implementation is determined by local governments, usually on a case-by-case basis.

There are three main forms of conducting public discussions:

- placing environmental impact assessment materials in libraries and collecting comments to them through questionnaires;

- public participations with the invitation of all those wishing and the presentation of representatives of the customer and other interested parties;

- open days which can also be attended by anybody, but where no specific speakers are present: the participants of the event communicate and ask questions to the representatives of the customer in free form.

The legislation does not strictly regulate the forms of conducting public discussions within the EIA process, so there may be other forms.

It should be emphasized that public participations are just a form of public discussions. 
The Town Planning Code of the Russian Federation No. 190-FZ dated December 29, 2004 (as amended on 30.12.2008) provides for mandatory holding of public hearings.

The procedure for organizing and holding public hearings is determined by the charter of the municipal formation and (or) the regulatory legal acts of the representative body of the municipal formation, taking into account the provisions of Articles 28, 31, 39, 40, 46 of the Town Planning Code of the Russian Federation [15] [2].

For example, the Charter of the urban okrug stipulates that the procedure for organizing and holding public hearings is determined by the regulatory legal acts of the representative body of the urban okrug (for example, the Regulations).

Public hearings may be initiated by: the population of the urban okrug, the local council, the mayor of the city. Public hearings are scheduled by the decision of the local council or by the resolution of the mayor of the city, in accordance with the competence. The authorized body for holding public hearings is the organizing committee, which includes officials of the municipal formation administration, deputies of the local council and representatives of the public.

The decision on approving the above documents or rejecting and forwarding them for the finalization is made by the local governments taking into account the protocols of public hearings and conclusions on the results of such public hearings.

Recently, the legal experts have been focusing on the institution of public control, which allows citizens to exercise supervisory functions in relation to the authorities [9]. Public participations and public hearings are a form of public control.

Despite the fact that the Federal Law "On Basic Principles of Public Control in the Russian Federation" [1] provided for such a form of public control as direct participation of citizens in the local governance only in 2014, the institution of public hearings received a legal settlement and practical implementation much earlier by the Federal Law "On the General Principles of the Organization of Local Self-Government in the Russian Federation" dated October 6, 2003 [2].

A comparative analysis of public participations and public hearings reveals both similarities and significant differences. Public hearings are considered as a necessary form of municipal democracy which allows discussing drafts of municipal legal acts on issues of local importance with the participation of the municipal formation residents. They are held at the initiative of the representative body or the head of the municipal formation, as well as at the initiative of the public.

Public participations can be considered as a tool of public control.

Public participations are held on issues of state and municipal management in the energy field, urban development, procurement of goods, works, services to ensure state and municipal needs, as well as in other fields established by federal, regional and municipal legal acts.

Thus, in respect to the subject of legal regulation, public participations are much broader than municipal public hearings. The latter are not only limited to the municipal level, but also essentially confined to the discussion of drafts of municipal legal acts. The law specifies the types of legal acts of the municipal formation which must necessarily be submitted to public hearings:

- draft charter of the municipal formation, as well as drafts of municipal legal acts on introducing amendments and additions to the charter;

- draft local budget and report on its implementation;

- draft plans and programs for the development of the municipal formation, draft land use and development regulations, draft territorial planning regulations, draft rules for the improvement of territories, etc.;

- issues of the transformation of the municipal formation. 
Thus, public hearings aim to discuss not the activities of municipal bodies and organizations, but only drafts of municipal legal acts to be adopted. For that reason, norms of both above-mentioned laws are inconsistent in regards to public participations and public hearings. Legal inconsistency could easily be corrected by complementing Article 28 of the Federal Law "On the General Principles of the Organization of Local Self-Government in the Russian Federation" by the rule that public hearings can be held for discussion not only of draft municipal legal acts but also of other issues of local significance, including those relating to the activities of local governments and having public significance both for the public and for public organizations operating on the territory of the municipal formation. T.N. Miheeva and N.S. Vavilov believe that it is possible to extend public control to the area of implementation of certain state powers by local governments [8].

Some of the procedures for public participations and public hearings are similar: advance publication of information on issues of public participations and public hearings, on the date, time and place of their conduct. However, municipal public hearings received a more complete settlement: not only in the Federal Law, but also in the charters of municipal formations or special provisions adopted by representative bodies.

At the same time, only Article 25 of the Federal Law "On Basic Principles of Public Control in the Russian Federation" is dedicated to public participations, which is insufficient. Obviously, these issues require more extensive regulation by the laws of the federal subjects of the Federation or by the new provisions on public control in municipal formations.

However, the comparison of the legal norms governing the final documents prepared on the basis of public participations and public hearings clearly reveals that the legislation on public control is more fully developed. Based on the results of the public participations, the organizer prepares a final document (protocol) containing general information on the progress of public participations, including the opinions of their participants, proposals and statements received and recommendations approved by the majority of participants. The final document (protocol) is sent to the state authorities, local governments and other bodies and organizations with respect to which public control was exercised. The protocol is also subject to compulsory disclosure, including placement on the Internet.

In accordance with Article 26 of the Federal Law "On Basic Principles of Public Control", the above-mentioned bodies and organizations are obliged to review the documents sent to them and, within the legally established period, send substantiated responses to the relevant subjects of public control. The legislative norm on the compulsory consideration of the results of public participations and the giving of a substantiated response compares favorably with the legal guidelines regarding the results of municipal public hearings. The legislation on local government does not contain similar norms, denoting only the publication (promulgation) of the results of public hearings.

To complete the analysis of the legal institutions of public participations and municipal public hearings, we should note that they establish the legal framework for publicity of the forms of the population participating in the local life processes, both through public control and through consideration of drafts of municipal legal acts. In both cases, the interests of local governments are brought closer to those of citizens and public structures [16]. However, in order to enhance these processes, it is necessary to improve the legal framework at the level of federal and regional legislators and representative bodies of local government. In our opinion, the latter can fill the legal vacuum much faster and more efficiently.

Based on the above, it is necessary to focus on practical suggestions for improving public hearings, namely:

- expansion of variable forms of holding public hearings; 
- establishment of the clear grounds for refusing the initiative group of citizens to hold public hearings in municipal provisions on public hearings;

- establishment of the regulatory framework of the grounds for holding repeated public hearings on the same topic;

- establishment of the normative restriction for the number of municipal and state employees on the commissions for holding public hearings;

- distinction of the concepts of "the right to participate..." and "the right to speak..." in the municipal provisions on public hearings: "the right to speak ..." should be assigned to the population, social or professional groups of the municipal formation;

- federal level normative consolidation of the rules for time frames and places for conducting public hearings;

- legislative consolidation of the ban on the same composition of participants holding public hearings which simultaneously deal with different issues and objects and are located in different parts of the municipal formation;

- federal level consolidation of the ban on voting on issues submitted to public hearings in order to determine the results of public hearings in the form of recommendations reflecting the opinion of the majority of participants in public hearings;

- normative consolidation of the grounds for taking or not taking into account the results of hearings by local authorities and officials.

Unfortunately, currently existing public hearings in many ways resemble an organized rally of residents notified of its conduct. Usually, it is difficult to predict what number of residents will wish to participate, how representative the participants will be, to what extent the opinion of participants in public hearings will reflect the prevailing opinion of the population of the territory.

At the same time, the most promising direction for improvement of the technology of holding public hearings appears to be improvement of its regulatory framework, including the establishment of such forms of holding that will ensure (as in the case of veche (A popular assembly in medieval Slavic countries) meetings) organized and regular participation of legitimate representatives of neighborhoods, streets, bodies of territorial public self-government and other significant communities of local residents. Obviously, such a procedure for holding public hearings will reduce their similarity to rallies and the likelihood of distorting the true opinion of the population and will help to establish a permanent and productive dialogue between residents and authorities, which is vital to Russian public authorities in the present difficult socio-economic conditions.

A comparative legal analysis of the provisions on public hearings allows us to conclude that the legal regulation of this institution at the municipal level is rather low-quality. Many fundamentally important issues that directly determine the effectiveness of public hearings are outside the field of legal regulation. Much remains to be done in order to turn public hearings into a working mechanism for dialogue between local governments and the population.

During the participations, the initiators of economic activities explain their intentions, substantiate the proposed project activity and let interested participants comment on the project or propose changes to it.

Holding public participations is possible for any project that affects the interests of society, and it is necessary when the proposed project of economic activity requires a state environmental assessment. Public participations are most effective when all interested groups express their views and when the discussion takes place in an environment of mutual trust. 
Participants of public participations are the customer (the initiator of economic activity), executive authorities and local government, the public whose interests may be directly or indirectly affected by the proposed economic activity.

The success and effectiveness of public participations for all participants largely depend on the competence of the preparation and conduct and logic of completion.

Pro forma public participations usually do not bring the desired result to either their organizers or their participants.

It is important to note possible errors in organizing public participations:

On the part of the organizer of the participations:

- non-registration or incorrect registration of the participants;

- absence of the procedure for conducting the participations;

- incompetence of the moderator;

- violation of the procedure for keeping a record of participations;

- non-documentation of the achieved results.

On the part of the initiators of the proposed economic activity:

- conscious complication and extension of the report on the proposed project activity;

- drawing attention only to the conflicts of situations and participants;

- ignoring alternative options for activities and opponents;

- misleading the audience in the context of the implementation of the consensus reached.

On the part of the public (local population):

- incompetence in the issues of the project to be discussed;

- lack of orientation towards satisfying the interests of the public/population in the long run;

- lack of alternatives to the activities proposed by the initiator of the project;

- lack of focus on the essence of the project under discussion, possible risks and consequences.

\section{Conclusion}

In the energy field a special attention is paid to the interaction of economic entities with the authorities, namely local governments. This interaction appears in the form of public participations and public hearings.

However, holding public participations and public hearings in the energy field faces a number of challenges:

- related to the improvement of the general procedure of holding public participations / public hearings and widening the range of its forms;

- related to the procedural issues of the appointment of public participations / public hearings;

- related to the procedural issues of forming and determining the composition of the commission for holding public participations / public hearings;

- related to designating the persons invited to participate in public participations / public hearings;

- related to the time and place for conduct of public participations / public hearings;

- related to the list of issues submitted for public participations / public hearings and to informing the public about upcoming public participations / public hearings;

- caused by the low turnout for public participations / public hearings;

- related to the procedural issues of conducting public participations / public hearings; 
- related to summarizing the public participations / public hearings held;

- related to taking into account the results of public participations / public hearings held. In our study, we attempted to solve the above problems.

\section{References}

1. Federal Law No. 212-FZ (2014)

2. Federal Law No. 131-FZ (2003)

3. Ye.V. Fugalevich, M.V. Mikhaylova, Sbornik materialov IV Mezhdunarodnoy nauchno-prakticheskoy konferentsii "Innovatsionnyye tekhnologii v servise", 95-97 (2016)

4. H. Runhaar, N. Polman, Land Use Policy 73, 11-19 (2018)

5. J. Tosun, B.G. Peters, Environmental Science \& Policy 82, 90-99 (2018)

6. L. Dogaru, Procedia - Social and Behavioral Sciences 93, 1344-1348 (2013)

7. M. Fujino, K. Kuriyama, K. Yoshida, Journal of Forest Economics 29(A), 62-67 (2017)

8. T.N. Miheeva, N.S. Vavilov, Vestnik Saratovskoy gosudarstvennoy yuridicheskoy akademii 6(95) (2013)

9. T.N. Miheeva, Mariyskiy yuridicheskiy vestnik 1(12) (2015)

10. M. Gherbi, Energy Procedia 18, 265-275 (2012)

11. N. Melnikova, Procedia - Social and Behavioral Sciences, 356-361 (2016)

12. Report on the environmental safety of the branch North-West Territorial Okrug of FSUE RosRAO for 2016 (2015)

13. Report on the environmental safety of the Leningrad Nuclear Power Plant for 2016 (2015)

14. Teoriya i praktika zashchity obshchestvennykh ekologicheskikh interesov na primere odnoy organizatsii. Posobiye dlya nachinayushchikh aktivistov-ekologov (ROO «Ekologicheskaya vakhta Sakhalina», Yuzhno-Sakhalinsk: izdatel'stvo «Lukomor'ye», 2010)

15. The Town Planning Code of the Russian Federation No. 190-FZ (2004)

16. To a Question of Interaction of Local Governments with the Population: Foreign Experience, Zakony Rossii: opyt, analiz, praktika 8 (2014)

17. //http://www.sbor.ru/ 